\title{
Process optimization for the characterization of wine from Burans (Rhododendron arboreum) flowers
}

\section{Utpreksha Thapliyal* and Khan Chand ${ }^{1}$}

Department of Post Harvest Process and Food Engineering, G.B. Pant University of Agriculture and Technology, Pantnagar, (Uttarakhand) India

'Department of Agricultural Engineering, School of Agricultural Sciences and Rural Development, Central University of Nagaland, Medziphema (Nagaland) India

Email: uthapliyal18@gmail.com;kcphpfe@gmail.com)

SUMMARY :

Burans is an indigenous flower with adequate nutritional attributes but short shelf-life under prevailing conditions. The study involves developing biotechnological product wine from Burans flowers using the dried form of yeast (Saccharomycescerevisiae). The three levels of temperature $\left(\mathrm{X}_{1}, 26^{\circ} \mathrm{C}\right.$, $30^{\circ} \mathrm{C}$, and $\left.34^{\circ} \mathrm{C}\right)$, total soluble solid $\left(\mathrm{X}_{2}, 24^{\circ} \mathrm{B}, 26^{\circ} \mathrm{B}\right.$ and $\left.28^{\circ} \mathrm{B}\right)$ and $\mathrm{pH}\left(\mathrm{X}_{3}, 4.0,4.5\right.$ and 5.0) were taken as the main process parameters. The fermentation was carried out for five days. After five days, the biochemical analysis of wine was done by quantifying alcohol by volume and titratable acidity. The first response, alcohol by volume, ranged between 6.6 per cent to 14.2 per cent. It was found to increase with increase in temperature and decrease with increase total soluble solid. However, on increasing the must's $\mathrm{pH}$, the alcohol by volume of the wine first increased and then dropped. The second response, titratable acidity, varied between $0.598-0.906 \mathrm{~g} / \mathrm{l}$. The titratable acidity of the wine initially decreased with an increase in temperature and later increased. The titratable acidity was directly related to the total soluble solids as it increased with increase in total soluble solid. Similarly, on increasing $\mathrm{pH}$, the titratable acidityincreased. The statistical analysis of this study showed that the temperature had a highly significant effect on alcohol by volume, i.e., 1 per cent level of significance, while $\mathrm{pH}$ was found to have a 1 per cent level of significance for titratable acidity. Therefore, from the present investigation, it can be concluded that an acceptable variety of wine can be produced from burans flowers, which can also reduce post-harvest losses.

KEY WORDS : Total soluble solid, Alcohol by volume, Titratable acidity, Post-harvest

How to cite this paper : Thapliyal, Utpreksha and Chand, Khan (2020). Process optimization for the characterization of wine from Burans (Rhododendron arboreum) flowers. Internat. J. Proc. \& Post Harvest Technol., 11(2) : 18-26. DOI: 10. 15740/HAS/IJPPHT/11.2/18-26. Copyright@2020: Hind Agri-Horticultural Society. 